http://dx.doi.org/10.23891/yyuni.2017.0

ISSN:1305-2020

\title{
Rehberli Sorgulama Ölçeğinin Geçerlik ve Güvenirlik Çalışması
}

\section{Şenol ŞEN*, Ayhan YILMAZ***}

Öz: Bu çalışmanın amacı Cheung (2011) tarafından geliştirilen Rehberli Sorgulama Ölçeğini Türkçeye uyarlamak, geçerlik ve güvenirlik çalışmalarını yapmaktır. Çalışmaya iki devlet üniversitesinin eğitim fakültesine devam etmekte olan 132 öğretmen adayı katılmıştır. Ölçek için çeviri işlemleri yapıldıktan sonra geçerlik çalışmaları için doğrulayıcı faktör analizi ve güvenirlik çalışmaları için ise Cronbach Alfa iç tutarlılık ve McDonald'ın Omega katsayıları hesaplanmıştır. Doğrulayıcı faktör analizi sonucunda 12 madde ve ilişkili üç alt boyuttan oluşan (rehberli sorgulamaya dayalı laboratuvarların önemi, geleneksel doğrulama laboratuvarlarının sınırlılıkları, rehberli sorgulamaya dayalı laboratuvarlarla ilgili uygulama sorunları) modelin iyi uyum gösterdiği belirlenmiştir $\left(\chi^{2} / s d=1.27, \quad R M S E A=.045\right.$, $S R M R=.051, C F I=.98, G F I=.92, A G F I=.88, N F I=.93, N N F I=.97, I F I=.98$ ). Ölçekte yer alan maddelerin, faktör yüklerinin istatistiksel olarak anlamlı ve.56 ile .85 arasında değerler aldığı tespit edilmiştir. Cronbach Alfa iç tutarlılık katsayısı rehberli sorgulamaya dayalı laboratuvarların önemi boyutu için .81, geleneksel doğrulama laboratuvarlarının sınırlılıkları boyutu için .76 ve son olarak rehberli sorgulamaya dayalı laboratuvarlarla ilgili uygulama sorunları boyutu için .83 olarak hesaplanmıştır. Sonuç olarak Rehberli Sorgulama Ölçeğinin Türkçe formunun geçerli ve güvenilir bir ölçek olduğu ifade edilebilir.

Anahtar Sözcükler: Rehberli Sorgulama, Geleneksel Doğrulama Laboratuvarları, Geçerlik, Güvenirlik

\footnotetext{
* Dr. Şenol ŞEN, Hacettepe Üniversitesi, Eğitim Fakültesi, OFMAE Bölümü, Kimya Eğitimi ABD, Ankara schenolschen@gmail.com

Prof. Dr. Ayhan YILMAZ, Hacettepe Üniversitesi, Eğitim Fakültesi, OFMAE Bölümü, Kimya Eğitimi ABD, Ankara ayhany@hacettepe.edu.tr
} 
The Study of Reliability and Validity of Guided-Inquiry Scale

Abstract: The aim of this study was to adapt the Guided-Inquiry Scale, developed by Cheung (2011), to Turkish and conduct the reliability and validity studies. The sample of this study consisted of 132 preservice teachers attending the faculty of education at two public universities. After translation procedures of the scale, confirmatory factor analysis was conducted to determine the construct validity and Cronbach Alpha internal consistency and McDonald's omega coefficients were calculated to identify reliability of the scale. The results of confirmatory factor analysis revealed that the adapted scale consisted of 12 items in 3 subscales and acceptable fit indices belonged to the model measuring three correlated different structures (the value of guided-inquiry labs, limitations of cookbook-style labs, and implementation issues with guided-inquiry labs) $\left(\chi^{2} / d f=1,27, R M S E A=.045, S R M R=.051\right.$, $C F I=.98, G F I=.92, A G F I=.88, N F I=.93, N N F I=.97, I F I=.98)$. The factor loadings obtained from confirmatory factor analysis were statistically significant and ranged from .56 to .85 . The Cronbach Alpha internal consistency coefficient was found to be.81 for the value of guided-inquiry labs dimension; .76 for limitations of cookbook-style labs dimension; .83 for implementation issues with guided-inquiry labs dimension. These results showed that the Turkish form of the Guided-Inquiry Scale is a valid and reliable instrument.

Keywords: Guided-Inquiry, Cookbook-Style Labs, Validity, Reliability 
http://dx.doi.org/10.23891/yyuni.2017.0

ISSN:1305-2020

Giriş

Son yıllarda öğrencilerin fen ve matematik gibi temel derslere yönelik ilgilerinde bir düşüş eğilimi vardır. $\mathrm{Bu}$ eğilimi gidermek, öğrencilerin derslere ilgilerini artırmak için hem ülkemizde hem de yurt dışında eğitimciler tarafından çeşitli projeler ve çalışmalar yapılmaktadır. Avrupa Komisyonu tarafından hazırlanan raporda, öğrencilerin bu ilgilerini artırmak için okullardaki fen öğretimi pedagojisinin tümdengelim yönteminden sorgulamaya dayalı yönteme dönüştürülmesi gerektiğgi vurgulanmıştır. Raporda, sorgulamaya dayalı fen eğitiminin hem ilköğretim hem de ortaöğretim öğrencilerinin ilgilerini ve becerilerini geliştirdiği ve öğretmenlerin motivasyonlarını artırdığı belirtilmiştir (Rocard ve dĭg., 2007). Amerikan Ulusal Araştırma Konseyi (National Research Council [NRC], 1996) de yine fen eğitiminin merkezinde sorgulamaya dayalı öğrenmenin olması gerektiğini savunmuştur.

Sorgulama; gözlemlerin yapıldığı, soruların sorulduğu, önceki bilgileri görmek için kitapların ve diğer kaynakların incelendiği, araştırmaların planlandığı, deneysel kanıtların varlığında önceki bilgilerin yeniden incelendiği, verilerin toplanıldığı, analiz edildiği ve bu verilerin yorumlanması için araçların kullanıldığı, cevapların, tahminlerin ve açıklamaların önerildiği ve sonuçların paylaşıldığı çok yönlü bir etkinliktir (NRC, 1996). Colburn (2000), sorgulamaya dayalı öğrenmeyi; öğrenciye yaparak yaşayarak öğrenme ortamının oluşturulması, açık uçlu ve öğrenci merkezli etkinliklere öğrencilerin katılımının sağlanması ve buna uygun bir sınıf ortamının yaratılması şeklinde açıklamıştır. Sorgulamaya dayalı öğrenme; öğrencilerin öğrenmeyi öğrenmelerinde ve üst düzey düşünme becerilerinin gelişiminde etkili olup yapılandırmacı yaklaşıma dayalı olarak ortaya çıkmıştır (Minner, Levy ve Century, 2010). Bu yöntemde öğrenciler, öğrenme sürecinin sorumluluğunu alarak öğrenme sürecine aktif olarak katılırlar, kendi sorularını oluştururlar, yeni bilgileri mevcut olan bilgileriyle bütünleştirerek öğrenirler (Llewellyn, 2002). Tuan, Chin, Tsai ve Cheng 
http://dx.doi.org/10.23891/yyuni.2017.0

ISSN:1305-2020

(2005) sorgulamaya dayalı öğrenmenin, anlamlı bilgilerin yapılandırılması ve bilimsel görevlerin araştırılması için öğrencilere firsatlar sunan açık uçlu bir öğrenme ortamı sağladığını belirtmişlerdir. Öğretmen ve öğrenci kontrolünün düzeyine göre dört farklı sorgulamaya dayalı öğrenme yöntemi vardır. Bunlar; doğrulayıcı, yapılandırılmış, rehberli ve açık uçlu sorgulamaya dayalı öğrenme yöntemleridir (Windschitl, 2003). Yapılandırmacı yaklaşımın teorik temelleri dikkate alındığında ve sorgulamaya dayalı öğrenme türleri incelendiğinde, rehberli sorgulamaya dayalı öğrenme yönteminin yapılandırmacı yaklaşımla daha uyumlu olduğu ve diğer sorgulamaya dayalı yöntemlerle karşılaştırıldığında daha etkili sonuçlar ortaya çıkardığı belirlenmiştir (Minner ve diğ., 2010). Bu yöntemde öğrenciler, spesifik bir probleme çözüm bulabilmek için deney yapabilme şansı yakalamakta, sonuçları analiz etmekte ve ampirik veriye dayalı olarak da kendi sonuçlarını elde edebilmektedirler (Hofstein ve Walberg, 1995; Montes, Lai ve Sanabria, 2003).

Sorgulamaya dayalı laboratuvarlara göre düzenlenmiş olan etkinlikler; öğrencilerin anlamlı öğrenmelerine, kavramsal öğrenmelerine ve bilimin doğasını anlamalarına olumlu yönde katkı sağladığı literatürde yapılan çalışmalarda açıklanmıştır (Dori, Sasson, Kaberman ve Herscovitz, 2004; Hodson, 1990; Hofstein ve Lunetta, 1982; 2004; Tobin, 1990). Laboratuvarlar, sorgulamaya dayalı öğrenme için en uygun ortamlardan biridir (Hofstein ve Lunetta, 2004). Sorgulamaya dayalı laboratuvar etkinliklerinin fen bilimleri öğretimi müfredatında önemli bir rolü bulunmakta ve fen eğitimcileri de sorgulamaya dayalı laboratuvar etkinliklerine katılan öğrencilerin kazanımlarının fazla olduğunu belirtmişlerdir (Backus, 2005; Deters, 2005; Friel, Albaugh ve Marawi, 2005; Gibson ve Chase, 2002; Lord ve Orkwiszewski, 2006). Cheung (2011) rehberli sorgulamaya dayalı laboratuvarları, öğretmen tarafından sorulan bir soruya öğrencilerin cevap vermek amacıyla tasarladıkları deneysel süreç (verilerin toplanması ve sonuçların yorumlanması)şeklinde tanımlanmıştır. Alternatif olarak sorgulamaya dayalı laboratuvarlar, öğretmen tarafından anlatılmamış olan 
http://dx.doi.org/10.23891/yyuni.2017.0

ISSN:1305-2020

yeni kimya kavramlarının anlaşılması için öğrencilerin kendilerine verilmiş olan deneysel süreci takip ettikleri laboratuvarlar şeklinde de ifade edilebilir.

Çalışmanın Amacı ve Önemi: Literatürde yapılan çalışmalarda, sorgulamaya dayalı laboratuvarların öğrencilerin konuları öğrenmelerine, bilimsel süreç becerilerinin gelişmesine, fen derslerine karşı tutumlarına ve motivasyonlarının artmasına, bilimin doğasını anlamalarına ve iletişim becerilerinin gelişmesine önemli ölçüde katkı sağladığ1 açıklanmıştır (Backus, 2005; Bayram, Oskay, Erdem, Özgür ve Şen, 2013; Beck, Butler ve da Silva, 2014; Deters, 2005; Friel ve diğ., 2005; Gibson ve Chase, 2002; Lord ve Orkwiszewski, 2006; Şeşen ve Tarhan, 2013; Yakar ve Baykara, 2014; Tuan ve diğ., 2005). Sorgulamaya dayalı öğrenmenin fen öğretiminde önemli bir yeri olmasına rağmen birçok öğretmen tarafından sorgulamaya dayalı öğrenme tercih edilmemektedir (Colburn, 2000). Çünkü öğretmenler, sorgulamanın anlamına yönelik karışıklıklar yaşamakta, sorgulamaya dayalı öğrenmenin sadece üst düzey becerileri olan öğrencilerle yapılabileceğini düşünmekte, sorgulamaya dayalı öğrenme için kendilerini yeterli hissetmemekte ve bu yöntemin sınıf ortamında uygulanmasının zor olduğuna inanmaktadırlar (Welch, Klopfer, Aikenhead ve Robinson, 1981). Bu noktadan hareketle geleceğin öğretmenleri olacak öğretmen adaylarının sorgulamaya dayalı laboratuvarlarla ilgili ne düşündüklerini ortaya çıkarmak önem kazanmaktadır. Literatür incelendiğinde, öğretmenlerin, öğretmen adaylarının ve öğrencilerin sorgulamaya dayalı öğrenme ile ilgili görüşlerinin belirlenmesi amacıyla mülakatların kullanıldığ1 nitel araştırmaların olduğu görülmektedir (Bayram, 2015; Duran, 2015; Cheung, 2007; Roehrig ve Luft, 2004; Şen, Y1lmaz ve Erdoğan, 2016). Fakat özellikle büyük örneklemlerle çalışılarak öğretmen adaylarının rehberli sorgulama ile ilgili görüşlerinin belirlenmesi ve nitel çalışmaların nicel araştırma sonuçlarıyla desteklenmesi için güvenilir ve geçerli ölçekler kullanılmalıdır. Yine yapılacak olan deneysel çalışmalar sonunda öğretmen adaylarının rehberli sorgulama ile ilgili görüşlerindeki değişimin izlenmesi için öntest ve 
http://dx.doi.org/10.23891/yyuni.2017.0

ISSN:1305-2020

sontest olarak uygulanabilecek ölçeklere de gereksinim duyulmaktadır. Fakat ulusal ve uluslararası literatür incelendiğinde rehberli sorgulamaya dayalı laboratuvar uygulamalarına yönelik olarak öğretmenlerin ve öğretmen adaylarının inançlarını ölçebilecek olan ölçeklerin sayısının da yeterli olmadığı belirlenmiştir. Bu nedenle bu çalışmada öğretmen adaylarının okullarda rehberli sorgulamaya dayalı laboratuvarlara yönelik inançlarını değerlendirmek amacıyla Cheung (2011) tarafından geliştirilen Rehberli Sorgulama Ölçeğinin Türkçe 'ye uyarlanması ve psikometrik özelliklerinin incelenmesi amaçlanmıştır.

\section{Yöntem}

Çalışma Grubu. Çalışmaya iki farklı devlet üniversitesinde okumakta olan toplam 132 kimya öğretmen adayı katılmıştır. Çalışmada amaçsal örnekleme yöntemi kullanılmıştır. Örneklem belirlenirken rehberli sorgulama ile ilgili bilgi ve deneyimleri olan öğretmen adayları belirlenmiştir. Çalışmaya 2., 3., 4. ve 5. sınıf öğretmen adayları katılmıştır. Öğretmen adaylarının tümüne rehberli sorgulamaya dayalı öğrenme ile ilgili bilgiler verilmiştir. Öğretmen adaylarının yaşları 18 ile 27 arasında değişmekte olup yaş ortalaması $21.03(\mathrm{sd}=1.82)$ olarak hesaplanmıştır. Çalışmaya katılan öğretmen adaylarının 102'si kadın ve 30’u da erkek öğrencidir.

Uygulama. Cheung, (2011) tarafından geliştirilen ölçeği Türkçe 'ye uyarlamak için yazarından gerekli izin alınmıştır. Daha sonra ölçek, hem İngilizce hem de Türkçe dillerini bilen dil uzmanı ve kimya eğitimi alanında uzman üç kişi tarafından Türkçeye çevrilmiştir. Uzmanların çevirilerinin ortak noktaları dikkate alınarak ölçeğin Türkçe formu oluşturulmuştur. Oluşturulan Türkçe form dil uzmanı tarafından tekrar İngilizceye çevrilmiştir. Türkçe ve İngilizce formlar arasındaki tutarlılık incelenmiştir. Türkçe form anlam ve gramer açısından incelenerek gerekli düzeltmeler yapılmıştır. Kimya eğitimi uzmanları tarafından gerekli düzeltmeler yapıldıktan sonra Türkçe form son şeklini almıştır. 
http://dx.doi.org/10.23891/yyuni.2017.0

ISSN:1305-2020

Esas uygulamaya geçilmeden önce Türkçe form 25 kimya öğretmen adayına uygulanarak içerik ve anlaşılırlık açısından kontrol edilmiş ve forma son şekli verilmiştir (bkz. EK A).

Veri Toplama Aracı. Çalışmada veri toplama aracı olarak Rehberli Sorgulama Ölçeği kullanılmıştır. Ölçek, Cheung (2011) tarafından ortaöğretim kimya laboratuvarlarında rehberli sorgulamaya dayalı laboratuvar etkinliklerinin uygulanmasına yönelik öğretmenlerin inançlarını belirlemek amacıyla geliştirilmiştir. Ölçek üç alt boyuttan ve 12 maddeden oluşmuştur. Bunlar; rehberli sorgulamaya dayalı laboratuvarların önemi, geleneksel doğrulama laboratuvarlarının sınırlılıkları ve rehberli sorgulamaya dayalı laboratuvarlarla ilgili uygulama sorunlarıdır. Rehberli sorgulamaya dayalı laboratuvarların önemi boyutunda dört madde yer almaktadır. (1, 4, 5 ve 9). Bu boyut, rehberli sorgulamaya dayalı laboratuvar etkinliklerinin öğrencilerin bilimsel süreç becerilerinin gelişmesinde önemli ve yararlı olup olmadığına yönelik inançlarıyla ilişkilidir. Geleneksel doğrulama laboratuvarlarının sinırlılıkları boyutunda dört madde bulunmaktadır (3, 6, 8 ve 11). Bu boyut, geleneksel doğrulama laboratuvarlarının rehberli sorgulama laboratuvarları ile karşılaştırıldığında öğrencilerin bilimsel süreç becerileri ve dersin içeriğinin anlaşılmasındaki etkilerine yönelik inançlarıyla ilişkilidir. Rehberli sorgulamaya dayalı laboratuvarlarla ilgili uygulama sorunları boyutunda ise yine dört madde yer almaktadır (2,7, 10 ve 12). Bu boyut, öğrencilerin rehberli sorgulama laboratuvarlarını genel olarak sevip sevmedikleri ve kimya müfredatında bu laboratuvarların uygulanabilir olup olmadığına yönelik inançlarıyla ilişkilidir.

Cheung (2011), kısa ve negatif maddelerin olmadığ 1 bir ölçek oluşturmayı amaçlamıştır. $\mathrm{Bu}$ amaçla araştırmacı tarafından 30 maddelik bir madde havuzu oluşturulmuştur. Ölçekte yer alan ifadeler "Benim için kesinlikle yanlış (1)" ve "Benim için kesinlikle doğru(7)" şeklinde 7’li likert tipi ölçek üzerinde değerlendirilmektedir. Araştırmacı tarafından ölçeğin güvenirliği için Cronbach Alfa iç tutarlılık katsayısı ve madde toplam korelasyonları incelenmiş olup yapı geçerliliğini sağlamak için doğrulayıcı faktör analizi 
http://dx.doi.org/10.23891/yyuni.2017.0

ISSN:1305-2020

yapılmıştır. Orijinal ölçeğin geliştirilme çalışmasına 200 kimya öğretmeni katılmıştır. 200 kimya öğretmeni arasından rastgele seçilen 50 kimya öğretmeni ile madde analizi yapılmıştır. 50 öğretmenin, 30 maddeye verdiği cevaplar için madde toplam korelasyonları ve Cronbach Alfa iç tutarlılık katsayıları incelenmiştir. Daha sonra her bir alt boyutta yer alan ve madde toplam korelsyonu en yüksek olan dört madde toplam da 12 madde belirlenmiştir. 12 maddeden oluşan ölçeğin son hali 150 öğretmene uygulanarak yapı geçerliği için doğrulayıcı faktör analizi yapılmıştır. Ölçeğin 12 maddelik versiyonuna ait Cronbach Alfa iç tutarlılık katsayıları .74 ile .79 arasında değişmekte ve madde toplam korelasyonları ise .45 ile .69 arasında değerler almıştır. Doğrulayıcı faktör analizi sonucunda ise faktör yüklerinin anlamlı olduğu ve t değerlerinin 5.78 ile 7.79 arasında değiştiği belirtilmiştir. Cheung uyum indekslerinin ( $\mathrm{GFI}=.91, \mathrm{CFI}=.93, \mathrm{NNFI}=.91, \mathrm{IFI}=.93)$ uyum iyiliği kriterlerini karşıladığını ifade etmiştir.

Verilerin Analizi. Örneklem yeterliliğinin belirlenmesi ve verilerin faktör analizi için uygun olup olmadığının tespit edilmesi amacıyla Kaiser-Meyer-Olkin (KMO) ve Bartlett Küresellik testleri yapılmıştır. Kaiser-Meyer-Olkin, gözlenen korelasyon katsayıları büyüklüğü ile kısmi korelasyon katsayılarının büyüklügünü karşılaştırmaktadır. KaiserMeyer-Olkin oranının 0.50 'in üzerinde olması beklenilmektedir. Bu oranın yüksek olması, veri setinin faktör analizi için uygun olduğunu gösterir. Tablo 1'de Kaiser- Meyer-Olkin ve Bartlett Küresellik testleri sonuçları verilmiştir.

Tablo1. KMO ve Bartlett küresellik test sonuçları

\begin{tabular}{clr}
\hline \multicolumn{2}{l}{ KMO Örneklem Yeterliliği Testi } & .815 \\
\hline \multirow{2}{*}{ Bartlett's } & \multicolumn{1}{c}{ Ki-Kare } & 598.098 \\
\cline { 2 - 3 } Küresellik testi & $\mathrm{sd}$ & 66 \\
\cline { 2 - 3 } & $\mathrm{p}$ & .000 \\
\hline
\end{tabular}


http://dx.doi.org/10.23891/yyuni.2017.0

ISSN:1305-2020

Tablolincelendiğinde, .815 değeri veri setinin faktör analizi için uygun olduğunu göstermektedir. Bartlett testi sonucunun .05 anlamlılık düzeyinde anlamlı olması; değişkenler arasında yüksek korelasyonun ve veri setinin faktör analizi için uygun olduğunu ortaya koymaktadır.

Ölçeğin yapı geçerliği için doğrulayıcı faktör analizi yapılmıştır. Ölçeğin güvenirliği için Cronbach Alfa iç tutarlılık ve McDonald'ın Omega katsayıları hesaplanmış ve madde analizi ise madde-toplam korelâsyonuyla incelenmiştir. Verilerin analizi için SPSS ve Lisrel programları kullanılmıştır.

\section{Bulgular}

Bu bölümde ölçeğin yapı geçerliği için yapılan doğrulayıcı faktör analizi sonucunda üç farklı modele ait sonuçlar verilmiştir. Çalışmada denenen ilk model tüm maddelerin tek bir yapıyı ölçtüğü model, ikinci model 12 maddenin ilişkisiz üç farklı yapıyı ölçtüğü model ve son olarak da 12 maddenin ilişkili üç farklı yapıyı ölçtüğü model şeklindedir. Doğrulayıcı faktör analizi sonucunda kabul edilebilir ve daha iyi uyum indekslerinin ilişkili üç farklı yapıyı ölçen modele ait olduğu belirlenmiştir. Doğrulayıcı faktör analizi sonucunda 12 maddenin ilişkili üç farklı yapıyı ölçtüğü modele ait path diyagramı ve standart katsayılar Şekil 1' de yer almaktadır. 


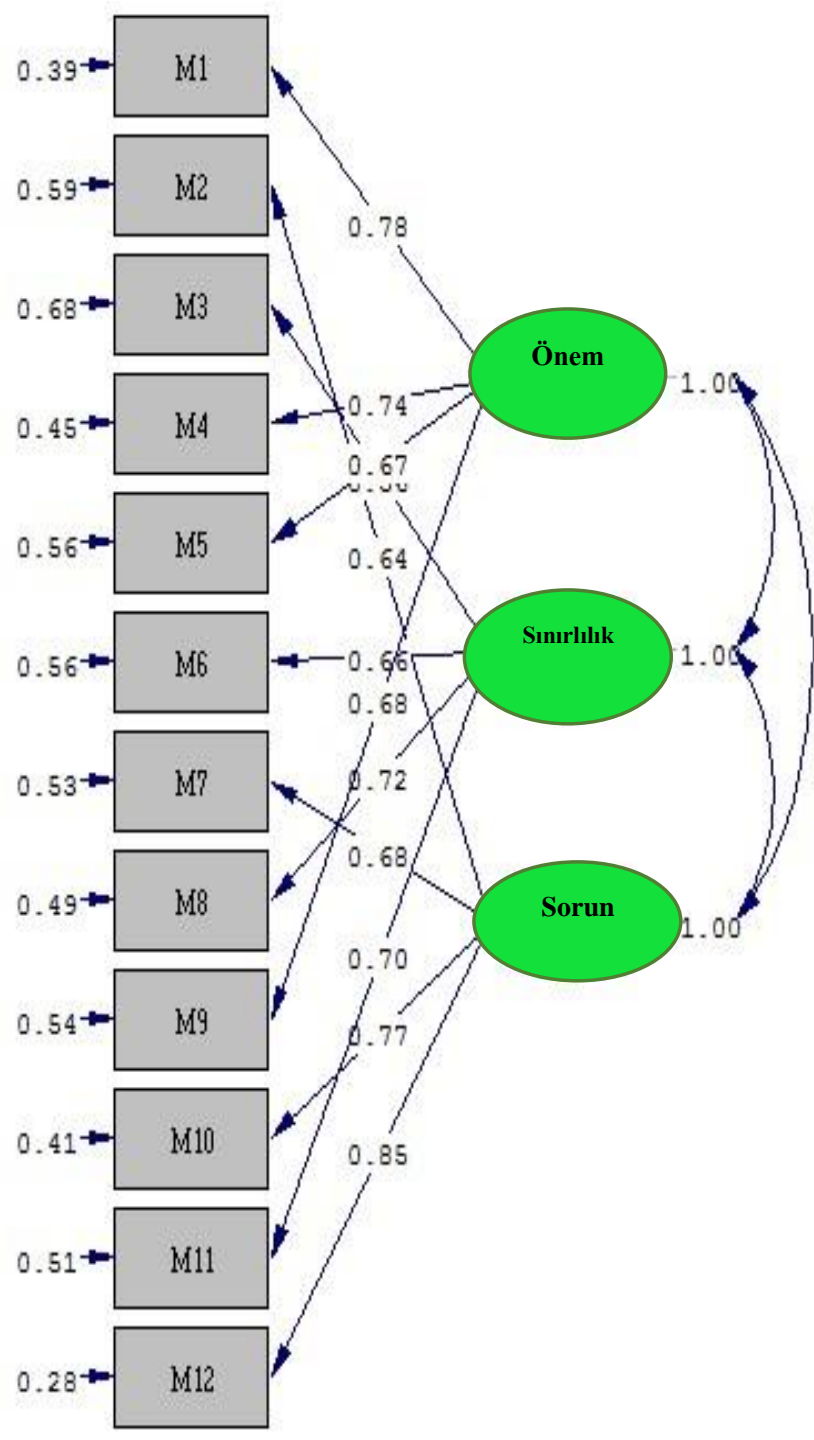

Chi-Square $=64.80, \mathrm{df}=51, \mathrm{p}-\mathrm{value}=0.09265, \mathrm{RMSEA}=0.045$

Şekil 1. Rehberli Sorgulama Ölçeğine İlişkin Path Diyagramı ve Faktör Yükleri 
http://dx.doi.org/10.23891/yyuni.2017.0

ISSN:1305-2020

Tablo 2. Rehberli Sorgulama Ölçeği Verilerinin Model-Veri Uyum Değerleri

\begin{tabular}{|c|c|c|c|c|c|c|c|c|c|}
\hline \multirow[b]{2}{*}{ Model } & \multicolumn{9}{|c|}{ Veri-model uyum indeksleri (kabul edilebilir uyum değerleri) } \\
\hline & $\chi^{2} / \mathbf{d f}$ & RMSEA & SRMR & CFI & GFI & AGFI & NFI & NNFI & IFI \\
\hline & $(<3,0)$ & $(<.08)$ & $(<.1)$ & $(>.95)$ & $(>.90)$ & $(>.85)$ & $(>.90)$ & $(>.95)$ & $(>.90)$ \\
\hline $\begin{array}{c}\text { Model I: Tek } \\
\text { Faktörlü Model }\end{array}$ & 4.36 & .160 & .12 & .84 & .77 & 67 & .80 & .80 & .84 \\
\hline Model II: Üç & & & & & & & & & \\
\hline $\begin{array}{l}\text { Faktörlü } \\
\text { (İlişkisiz) }\end{array}$ & 2.31 & .100 & .21 & .90 & .86 & .80 & .86 & .88 & .90 \\
\hline $\begin{array}{c}\text { Model III: Üç } \\
\text { Faktörlü (İlişkili) }\end{array}$ & 1.27 & .045 & .051 & .98 & .92 & .88 & .93 & .97 & .98 \\
\hline
\end{tabular}

Tablo 2'de doğrulayıcı faktör analizleri sonucunda üç farklı model için elde edilen uyum indeksleri verilmiştir. Elde edilen uyum indeksleri $\left(\chi^{2} / s d=1.27, \quad R M S E A=.045\right.$, $S R M R=.051, C F I=.98, \quad G F I=.92, \quad A G F I=.88, \quad N F I=.93, \quad N N F I=.97, \quad I F I=.98)$ ilişkili üç faktörlü modelin iyi uyum verdiğini ortaya koymuştur(Çelik ve Yılmaz, 2013; Çokluk, Şekercioğlu ve Büyüköztürk, 2012; Schermelleh-Engel, Moosbrugger ve Müller, 2003; Sümer, 2000). Tablo 3'de ilişkili üç faktörlü modele ait doğrulayıcı faktör analizi sonucu elde edilen değerler, madde toplam korelasyonları, Cronbach Alfa iç tutarlılık ve McDonald'ın Omega katsayıları verilmiştir. 
http://dx.doi.org/10.23891/yyuni.2017.0

ISSN:1305-2020

Tablo 3. İlişkili Ü̧̧ Faktörlü Modele ait Doğrulayıcı Faktör Analizi Sonucu Elde Edilen $\lambda_{x}$, $\delta$, $t, R^{2}, \alpha$ ve $\omega$ Değerleri

\begin{tabular}{|c|c|c|c|c|c|c|c|c|}
\hline & & & & & & Madd & & \\
\hline Alt Boyutlar & $\begin{array}{l}\text { Miadde } \\
\text { No }\end{array}$ & $\lambda_{\mathrm{x}}$ & $\delta$ & $\mathbf{t}$ & $\mathbf{R}^{2}$ & $\begin{array}{l}\text { Top. } \\
\text { Kor. }\end{array}$ & $\alpha$ & $\omega$ \\
\hline & 1 & .78 & .39 & 9.83 & .61 & .57 & & \\
\hline & 4 & .74 & .45 & 9.18 & .55 & .46 & & \\
\hline & & & & & & & & .81 \\
\hline Önomi & & $.0 /$ & .36 & 7.99 & .45 & .30 & & \\
\hline & 9 & .68 & .54 & 8.17 & .46 & .50 & & \\
\hline & 3 & .56 & .68 & 6.11 & .31 & .50 & & \\
\hline & 6 & .66 & .56 & 7.38 & .44 & .40 & & \\
\hline & 8 & .72 & .49 & 8.09 & .52 & .54 & & \\
\hline & 11 & .70 & .51 & 7.89 & .49 & .44 & & \\
\hline Rehberli Sorgulamaya & 2 & .64 & .59 & 7.74 & .41 & .56 & & \\
\hline Dayalı Laboratuvarlar & 7 & .68 & .53 & 8.40 & .46 & .56 & & \\
\hline ile ilgili Uygulama & 10 & .77 & .41 & 9.85 & .59 & .38 & (0J & (05 \\
\hline Sorunları & 12 & .85 & .28 & 11.26 & .72 & .64 & & \\
\hline
\end{tabular}

Tablo 3'de her bir maddeye ait faktör yükü $\left(\lambda_{x}\right)$, hata varyansı $(\delta), \mathrm{t}$ değerleri ve açıklanan varyans değerleri verilmiştir. Ölçekte yer alan maddelerin t değerlerinin 2.56 değerinden daha büyük olduğu ve .01 düzeyinde anlamlı olduğu belirlenmiştir. Ayrıca doğrulayıcı faktör analizi sonucunda faktör yüklerinin $.56-.85$ arasında değiştiği tespit edilmiştir. Ölçekte yer alan maddelerin her biri için maddenin ölçeğin tamamı ile tutarlılığının bir göstergesi olan madde toplam korelasyon değerleri verilmiştir. Yapılan 
http://dx.doi.org/10.23891/yyuni.2017.0

ISSN:1305-2020

analizler sonucunda ölçeğin madde toplam korelasyon katsayılarının .30 ile .64 arasında değiştiği belirlenmiştir. Ölçeğin güvenirlik çalışmaları için hesaplanan Cronbach Alfa iç tutarlılık katsayısı; rehberli sorgulamaya dayalı laboratuvarların önemi boyutu için .81, geleneksel doğrulama laboratuvarlarının sınırlılıkları boyutu için .76 ve son olarak rehberli sorgulamaya dayalı laboratuvarlarla ilgili uygulama sorunları boyutu için .83 olarak bulunmuştur. Ayrıca konjenerik ölçmeler (faktör yüklerinin birbirine eşit olmadığı durumlar) için uygun olduğu ifade edilen McDonalds'ın Omega ( $\omega)$ katsayısı rehberli sorgulamaya dayalı laboratuvarların önemi boyutu için .81, geleneksel doğrulama laboratuvarlarının sınırlılıkları boyutu için .76 ve son olarak rehberli sorgulamaya dayalı laboratuvarlarla ilgili uygulama sorunları boyutu için .83 olarak hesaplanmıştır. Hem $\omega$ hem de $\alpha$ katsayılarının .70 üzerinde olması ölçme sonuçlarının güvenirliğinin bir göstergesidir. Tüm bu değerler incelendiği zaman ölçeğin güvenirlik kriterlerini sağladığı kabul edilmiştir.

\section{Sonuç ve Tartışma}

Bu çalışmada Cheung (2011) tarafından geliştirilen ölçek, ortaöğretim düzeyinde kimya öğretmen adaylarının rehberli sorgulamaya dayalı laboratuvar etkinlilerinin uygulanmasına yönelik inançlarını belirlemek amacıyla Türkçe 'ye uyarlanmıştır. Ölçeğin uyarlanması için izin alınmış olup ölçeğin yapı geçerliği için doğrulayıcı faktör analizi yapılmıştır. Doğrulayıcı faktör analizi sonucunda ilişkili üç faktörlü modelin yeterli düzeyde uyum gösterdiği kabul edilmiştir $\left(\chi^{2} / s d=1.27, \quad R M S E A=.045, \quad S R M R=.051, \quad C F I=.98\right.$, $G F I=.92, \quad A G F I=.88, \quad N F I=.93, \quad N N F I=.97, \quad I F I=.98)$. Güvenirlik çalışmaları için ise Cronbach Alfa iç tutarlılık katsayısı $(\alpha)$ ve ölçekteki maddelerin faktör yükleri birbirine eşit olmadı̆̆ı için McDonald'ın Omega katsayısı( $\omega)$ hesaplanmıştır. Hem $\omega$ hem de $\alpha$ katsayılarının .70 üzerinde olmasından dolayı ölçeğin güvenirlik kriterlerini sağladığı kabul edilmiştir. 
http://dx.doi.org/10.23891/yyuni.2017.0

ISSN:1305-2020

$\mathrm{Bu}$ çalışma ile Türkçe 'ye uyarlanan Rehberli Sorgulama Ölçeğinin alana katk1 sağlayacağı düşünülmektedir. Çünkü Cheung (2011) öğretmenlerin sorgulamaya dayalı laboratuvar deneylerini uygulamaya yönelik inançlarının neler olduğunu ve bu inançlarının nasıl ölçülebileceğinden yola çıkarak bir ölçeğe gerek duyulduğunu ifade etmiştir. Ulusal ve uluslararası literatüre bakıldığı zaman da rehberli sorgulamaya dayalı laboratuvar uygulamalarına yönelik öğretmenlerin ve öğretmen adaylarının inançlarını ölçebilecek geçerli ve güvenilir bir ölçeğin olmadığı belirlenmiştir.

Sonuç olarak yapılan analizler çerçevesinde12 madde ve üç alt boyuttan oluşan Rehberli Sorgulama Ölçeğinin ülkemizde kimya öğretmen adaylarının rehberli sorgulamaya dayalı laboratuvarlara yönelik inançlarını belirlemek için kullanılabilecek geçerli ve güvenilir bir ölçek olduğu söylenebilir. Rehberli sorgulamaya dayalı laboratuvarlara göre düzenlenmiş etkinlikler geliştiren ve uygulayan öğretmen adaylarının bu laboratuvarlara yönelik inançları ve inançlarındaki değişim(ler) bu ölçek ile ölçülebilir.

\section{Öneriler}

Hem ulusal hem de uluslararası literatürde öğretmen adaylarının sorgulamaya dayalı öğrenme ile ilgili görüşlerini belirlemek amacıyla çeşitli nitel araştırmalar yürütülmüştür. Nitel araştırmalarda örneklem büyüklüğü, verilerin toplanması, verilerin analiz edilmesi gibi süreçler daha uzun ve zor olabilmektedir. Fakat bu ölçek aracılığıyla öğretmen adaylarının rehberli sorgulama ile ilgili görüşleri daha kolay belirlenebilir. Daha büyük örneklemlerle yapılan çalışmalarda bu ölçekten yararlanılabilir.

Bu ölçek, kimya laboratuvarında rehberli sorgulamaya yönelik öğretmen adaylarının görüşlerini belirlemek amacıyla uyarlanmıştır. Yapılacak olan çalışmalarla biyoloji ve fizik gibi diğer fen bilimleri alanlarındaki öğretmen adaylarının laboratuvarlardaki rehberli 
http://dx.doi.org/10.23891/yyuni.2017.0

sorgulamaya dayalı uygulamalara yönelik görüşlerini belirlemek için ölçekler geliştirilebilir veya uyarlanabilir.

Deneysel çalıșmalar yapılarak öğretmen adaylarının rehberli sorgulama ile ilgili görüşlerindeki değişimler bu ölçek aracılığıyla incelenebilir.

Yine yapılacak olan çalışmalarda öğretmen adaylarının rehberli sorgulama ilgili görüşlerini etkileyen diğer faktörlerle ilişkisi korelasyonel çalışmalarla araştırılabilir.

\section{Makalenin Bilimdeki Konumu (Yeri)}

Matematik ve Fen Bilimleri Eğitimi Bölümü/Kimya Eğitimi Anabilim Dalı

\section{Makalenin Bilimdeki Özgünlüğü}

Son yıllarda sorgulamaya dayalı öğrenmenin önemi giderek artmakta ve bu yönde ülkemizde araştırmacılar tarafından çeşitli çalışmalar yürütülmektedir. Bu çalışmaların bir bölümü rehberli sorgulamaya dayalı laboratuvar etkinlikleri ile ilgili çalışmalar olup çalışma gruplarını da öğretmen adayları oluşturmaktadır. Bu çalışmalarda öğretmen adaylarının rehberli sorgulamaya dayalı laboratuvarlarla ile ilgili görüşlerinin incelenmesi gerekliliği önem kazanmaktadır. Bu değişimin izlenmesi için de ülkemizde kullanılacak Türkçe ölçeklerin olmadığı yapılan araştırmalar sonucu belirlenmiştir. $\mathrm{Bu}$ sebeple bu çalışma sonunda elde edilen Rehberli Sorgulama Ölçeğinin güvenilir ve geçerli Türkçe formu bundan sonra yürütülecek olan çalışmalarda kullanılabilir. 
http://dx.doi.org/10.23891/yyuni.2017.0

ISSN:1305-2020

\section{Kaynakça}

Backus, L. (2005). A year without procedures. The Science Teacher, 72(7), 54-58.

Bayram, Z. (2015). Öğretmen adaylarının rehberli sorgulamaya dayalı fen etkinlikleri tasarlarken karşılaştıkları zorlukların incelenmesi. Hacettepe Üniversitesi Ĕ̆itim Fakültesi Dergisi, 30(2), 15-29.

Bayram, Z., Oskay, Ö. Ö., Erdem, E., Özgür, S. D., \& Şen, Ş. (2013). Effect of Inquiry Based Learning Method on Students' Motivation. Procedia-Social and Behavioral Sciences, 106, 988-996.

Beck, C., Butler, A., \& da Silva, K. B. (2014). Promoting inquiry-based teaching in laboratory courses: are we meeting the grade? CBE-Life Sciences Education, 13(3), 444-452.

Çelik, H. E., \& Yılmaz, V. (2013). Lisrel 9.1 ile Yapısal Eşitlik Modellemesi (Yenilenmiş 2. Baskı). Ankara: Anı Yayıncılık.

Cheung, D. (2007). Facilitating chemistry teachers to implement inquiry-based laboratory work. International Journal of Science and Mathematics Education, 6 (1), 107-130.

Cheung, D. (2011). Teacher beliefs about implementing guided-inquiry laboratory experiments for secondary school chemistry. Journal of Chemical Education, 88(11), $1462-1468$.

Çokluk, Ö., Şekercioğlu, G., \& Büyüköztürk, Ş. (2012). Sosyal Bilimler için Çok Değişkenli İstatistik SPSS ve Lisrel Uygulamaları (2. Bask1). Ankara: Pegem Akademi.

Colburn, A. (2000). An inquiry primer. Science Scope, 23(6), 42-44. 
Deters, K.M. (2005). Student opinions regarding inquiry-based labs. Journal of Chemical Education, 82, 1178-1180.

Dori, Y.J., Sasson, I., Kaberman, Z., \& Herscovitz, O. (2004). Integrating case-based computerized laboratories into high school chemistry. The Chemical Educator, 9, 1-5.

Duran, M. (2015). Araştırmaya dayalı öğrenme yaklaşımına uygun rehber materyal geliştirme süreci ve öğrenci görüşleri. International Online Journal of Educational Sciences, $7(3), 179-200$.

Friel, R. F., Albaugh, C.E., \& Marawi, I. (2005). Students prefer a guided-inquiry format for general chemistry laboratory. The Chemical Educator, 10, 176-178.

Gibson, H.L., \& Chase, C. (2002). Longitudinal impact of an inquiry-based science program on middle school students' attitudes toward science. Science Education, 86, 693-705.

Hodson, D. (1990). A critical look at practical working school science. School Science Review, 70, 33-40.

Hofstein, A., \& Lunetta, V.N. (1982). The role of the laboratory in science teaching: Neglected aspects of research. Review of Educational Research, 52, 201-217.

Hofstein, A., \& Lunetta, V.N. (2004). The laboratory in science education: Foundations for the twenty-first century. Science Education, 88(1), 28-54.

Hofstein, A., \& Walberg, H.J. (1995). Instructional strategies. In B.J. Fraser \& H.J. Walberg (Eds.), Improving science education (pp. 70-89). Chicago: National Society for the Study of Education.

Llewellyn, D. (2002). Inquiry within: Implementing inquiry-based science standards. USA: Corwinn Press. 
http://dx.doi.org/10.23891/yyuni.2017.0

Lord, T., \& Orkwiszewski, T. (2006). Moving from didactic to inquiry-based instruction in a science laboratory. American Biology Teacher, 68(6), 342-345.

Minner, D. D., Levy, A. J., \& Century, J. (2010). Inquiry-based science instruction - what is it and does it matter? Results from a research synthesis years 1984 to 2002. Journal of research in science teaching, 47(4), 474-496.

Montes, I., Lai, C., \& Sanabria, D. (2003). Like dissolves like: A guided inquiry experiment for organic chemistry. Journal of Chemical Education, 80, 447-449.

National Research Council (1996). NationalScienceEducationStandards. National Academy of Science, Washington DC.

Rocard, M., Csermely, P., Jorde, D., Lenzen, D., Walberg-Henriksson, H., \& Hemmo, V. (2007). Science education now: A renewed pedagogy for the future of Europe. Brussels, Belgium: Directorate-General for Research, European Commission.

Roehrig, G.H., \& Luft, J.A. (2004). Constraints experienced by beginning secondary science teachers in implementing scientific inquiry lessons. International Journal of Science Education, 26, 3-24.

Schermelleh-Engel, K., Moosbrugger, H., \& Müller, H. (2003). Evaluating the fit of structural equation models: Tests of significance and descriptive goodness-of-fit measures. Methods of Psychological Research-Online, 8(2), 23-74.

Şen, Ş., Yılmaz, A., \& Erdoğan, Ü. I. (2016). Sorgulamaya Dayalı Laboratuvarlara İlişkin Öğretmen ～Adaylarının ～Görüşleri. İlköğretim ～Online, 15(2), 443-468. doi:http://dx.doi.org/10.17051/io.2016.25448 . 
Şeşen, B. A., \& Tarhan, L. (2013). Inquiry-based laboratory activities in electrochemistry:

High School Students' Achievements and Attitudes. Research in Science Education, 43(1), 413-435.

Sümer, N. (2000). Yapısal eşitlik modelleri: Temel kavramlar ve örnek uygulamalar. Türk Psikoloji Yazıları, 3(6), 49-74.

Tobin, K. (1990). Research on science laboratory activities: In pursuit of better questions and answers to improve learning. School Science and Mathematics, 90, 403-418.

Tuan, H. L., Chin, C. C., Tsai, C. C., \& Cheng, S. F. (2005). Investigating the effectiveness of inquiry instruction on the motivation of different learning styles students. International Journal of Science and Mathematics Education, 3, 541-566.

Welch, W., Klopfer, L., Aikenhead, G., \& Robinson, J. (1981). The role of inquiry in science education: Analysis and recommendations. Science Education, 65, 33-50.

Windschitl, M. (2003). Inquiry projects in science teacher education: What can investigative experiences reveal about teacher thinking and eventual classroom practice? Science education, 87(1), 112-143.

Yakar, Z., \& Baykara, H. (2014). Inquiry-based laboratory practices in a science teacher training program. Eurasia Journal of Mathematics, Science \& Technology Education, 10(2), 173-183. 
Ek A

\section{Rehberli Sorgulama Ölçeği}

Bu ölçekte yer alan ifadeler, öğretmen adaylarının rehberli sorgulamaya dayalı laboratuvar uygulamalarına yönelik görüşlerini belirlemek için hazırlanmıştır. Soruları yanıtlamak için aşağıdaki ölçütleri kullanın. Soruda geçen ifade sizin için kesinlikle doğru ise (7)'yi; sizinle ilgili kesinlikle yanlışsa (1)'i işaretleyin. Eğer ifadenin size göre doğruluğu bunlardan farklı ise sizin için en uygun düzeyi gösteren (1) ile (7) arasındaki rakamı işaretleyin.

\section{Benim için kesinlikle yanlış (1) (2) (3) (4) (5) (6)(7) Benim için kesinlikle doğru}

\begin{tabular}{|l|l|}
\hline $\begin{array}{l}\text { 1. Deneyler tasarlama kimya öğretim programının bir parçası } \\
\text { olmalıdır. }\end{array}$ & (1) (2) (3) (4) (5) (6)(7) \\
\hline $\begin{array}{l}\text { 2. Öğrencilerin çoğu, deney yapma sürecini planlama şansına sahip } \\
\text { oldukları laboratuvar çalışmalarını severler. }\end{array}$ & (1) (2) (3) (4) (5) (6)(7) \\
\hline $\begin{array}{l}\text { 3. Rehberli sorgulamaya dayalı laboratuvar çalışması, öğrencilerin } \\
\text { kimya bilgisini uygulamada geleneksel laboratuvar çalışmasına } \\
\text { göre daha fazla imkan sağlar. }\end{array}$ & (1) (2) (3) (4) (5) (6)(7) \\
\hline $\begin{array}{l}\text { 4. Bulgular eksik dahi olsa, öğrencilerin bir öğrenme aktivitesi } \\
\text { olarak verileri nasıl sunacakları ve analiz edecekleri konusunda } \\
\text { karar vermelerini istemek yararlıdır. }\end{array}$ & (1) (2) (3) (4) (5) (6)(7) \\
\hline $\begin{array}{l}\text { 5.Rehberli sorgulamaya dayalı deneyler fazla zaman almasına } \\
\text { rağmen önemli öğrenme aktiviteleridir. }\end{array}$ & (1) (2) (3) (4) (5) (6)(7) \\
\hline $\begin{array}{l}\text { 6. Rehberli sorgulamaya dayalı laboratuvar çalışması, öğrencilerin } \\
\text { kimya ile ilgili kavram yanılgılarına sahip olup olmadıklarını } \\
\text { ortaya çıkarmada geleneksel laboratuvar çalışmasına göre daha } \\
\text { etkilidir. }\end{array}$ & (1) (3) (4) (5) (6)(7) \\
\hline $\begin{array}{l}\text { 7. Öğgrencilerin çoğu rehberli sorgulamaya dayalı deneyleri } \\
\text { geleneksel laboratuvar çalışmalarından daha fazla sever. }\end{array}$ & (1) (2) (3) (4) (5) (6)(7) \\
\hline $\begin{array}{l}\text { 8. Rehberli sorgulamaya dayalı laboratuvar çalışması, öğrencilerin } \\
\text { çok sayıda pratik beceriler geliştirmesinde geleneksel laboratuvar } \\
\text { çalışmasına göre daha iyidir. }\end{array}$ & (1) (2) (3) (4) (5) (6)(7) \\
\hline $\begin{array}{l}\text { 9. Tasarımları yetersiz olsa bile, öğrencilerden bir öğrenme } \\
\text { aktivitesi olarak kendi deneylerini tasarlamalarını istemek }\end{array}$ & (1) (2) (3) (4) (5) (6)(7) \\
\hline
\end{tabular}


http://dx.doi.org/10.23891/yyuni.2017.0

ISSN:1305-2020

yararlidir.

10. Kimya derslerinde öğrencilerin kendi deneysel süreçlerini (1) (2) (3) (4) (5) (6)(7) tasarlamalarının uygulanabilir olduğuna inanıyorum.

11. Rehberli sorgulama yapan öğrenciler geleneksel doğrulama tipi (1) (2) (3) (4) (5) (6)(7) laboratuvar uygulamaları yapan öğrencilere göre yaptıkları hatalarından daha fazla öğrenebilirler.

12.Öğrenciler, her eğitim-öğretim yılında birkaç rehberli (1) (2) (3) (4) (5) (6)(7) sorgulamaya dayalı deney yapmalıdır. 